\title{
Recontextualizaciones en el convivio preescénico: una modalidad de enseñanza de la noción de conflicto a actores con padecimientos de salud mental
}

\section{Artículo de investigación}

\section{Ana Atorresi}

Universidad Nacional de Río Negro, Argentina aatorresi@unrn.edu.ar

\section{Gabriela Otero}

Grupo teatral El Brote

elbrotebariloche@yahoo.com.ar

$-$

Recibido: 3 de octubre de 2019

Aprobado: 3 de marzo de 2020

Cómo citar este artículo: Atorresi, Ana; Otero, Gabriela (2021). Recontextualizaciones en el convivio preescénico: una modalidad de enseñanza de la noción de conflicto a actores con padecimientos de salud mental. Calle 14: revista de investigación en el campo del arte 16(29). pp. 78-93.

https://doi.org/10.14483/21450706.17403

\section{(2) (1)}


guils: qi heguto girte is veres pe 4 verts $x i 1$ vido

to sls. Fe te gurdedo fuits

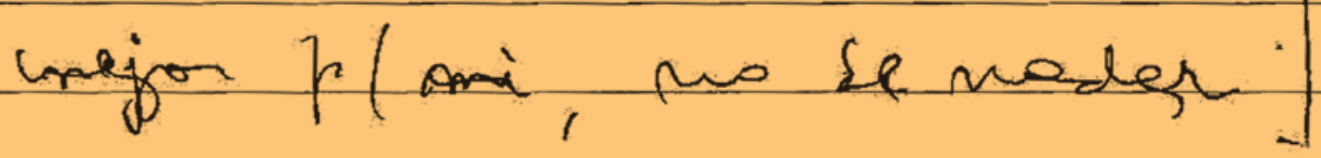

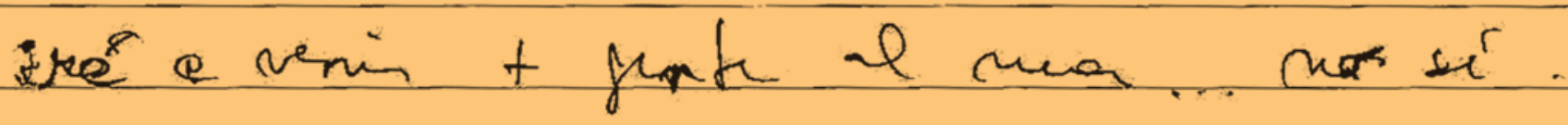

* punder í todo beè e frdo del mor be puodeen in.

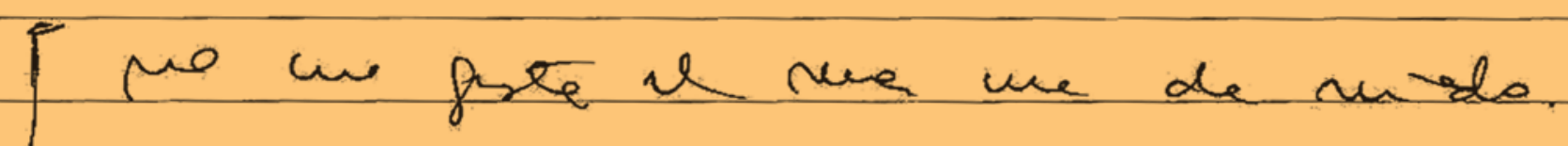

tté lovere il mer.

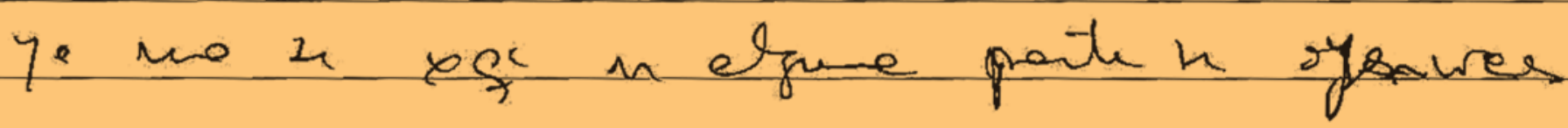
dibe the at teb fi mibe

Ste a riento...

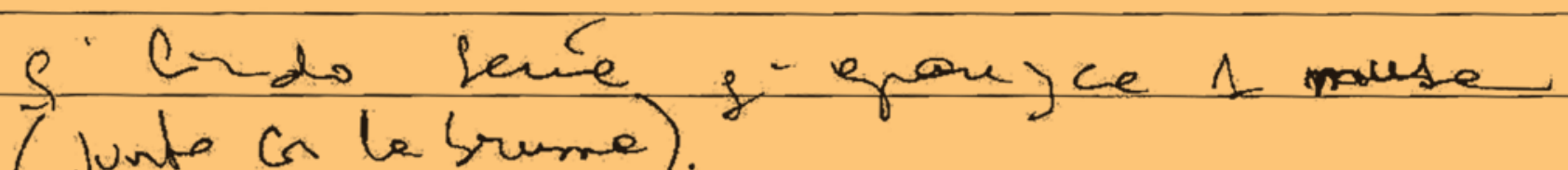

(Junte ca le brume).

\$C fero furde beb bruma - il no

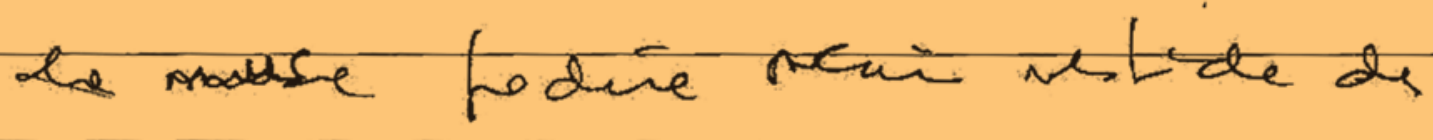

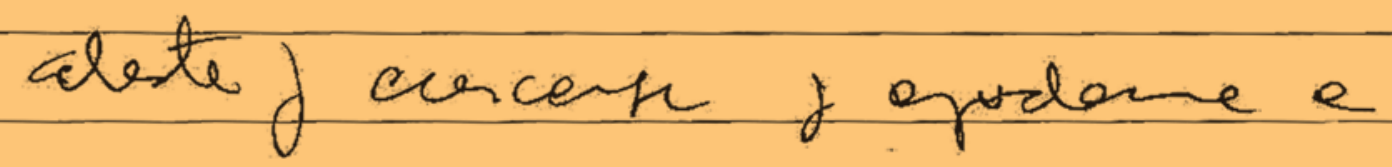

Cover le olga 
Recontextualizaciones en el convivio preescénico: una modalidad de enseñanza de la noción de conflicto a actores con padecimientos de salud mental

\begin{abstract}
Resumen
Tomando del campo teatral la noción de prácticas de escritura diversas y de la sociolingüística la noción de trayectorias textuales, el artículo describe la experiencia didáctica conducida por el grupo-escuela de teatro El Brote, radicado desde 1997 en la ciudad de Bariloche, provincia de Río Negro, Patagonia argentina, cuyos actores y actrices son personas con padecimientos de salud mental y en situación de desmanicomialización. El artículo ilustra en particular la enseñanza del concepto de conflicto junto a estos actores durante un período de dos años. La metodología empleada fue la reescritura de improvisaciones surgidas en el convivio preescénico hasta su condensación en un texto preescénico de autor. Los resultados de la experiencia muestran la asunción progresiva de juicio crítico y de una identidad profesional, lo que sugiere explorar más profundamente el efecto de la enseñanza teatral sostenida en las personas con padecimientos psíquicos.
\end{abstract}

\title{
Palabras clave
}

Desmanicomialización; didáctica del teatro; identidad profesional; prácticas de escritura; trayectorias textuales

Recontextualizations in the Pre-stage Coexistence: A Modality for Teaching the Notion of Conflict to Actors with Mental Health Conditions

\begin{abstract}
We borrow from the theatrical field the notion of diverse writing practices and from sociolinguistics the notion of textual trajectories, in order to describe the teaching experience conducted by the theater-school group El Brote, based since 1997 in the city of Bariloche, province of Rio Negro, Argentine Patagonia. The actors of this troupe are people with mental health conditions that are in the process of being deinstitutionalized. The article illustrates in particular the teaching of the concept of conflict along with these actors over a period of two years. The methodology used was the rewriting of improvisations that arose during pre-production until their condensation into a pre-performance author's text. The results of the experience show the progressive growth of critical judgment and a professional identity among the performers, which suggests exploring more deeply the effect of continuous actoral training for people with mental illness.
\end{abstract}

\section{Keywords}

Deinstitutionalization; theater education; professional identity; writing practices; textual trajectories

Recontextualisations dans la coexistence pré-théâtrale : une modalité pour enseigner la notion de conflit aux acteurs souffrant de troubles de santé mentale

\section{Résumé}

Nous empruntons au champ théâtral la notion de pratiques d'écriture diverses et à la sociolinguistique la notion de trajectoires textuelles, pour décrire l'expérience pédagogique menée par le groupe théâtre-école El Brote, basé depuis 1997 dans la ville de Bariloche, province de Rio Negro, Patagonie argentine. Les acteurs de cette troupe sont des personnes atteintes de troubles mentaux en cours de désinstitutionalisation. L'article illustre notamment l'enseignement de la notion de conflit auprès de ces acteurs sur une période de deux ans. La méthodologie utilisée a été la réécriture des improvisations qui ont surgi pendant la pré-production jusqu'à leur condensation dans le texte d'un auteur de pré-performance. Les résultats de l'expérience 
montrent la croissance progressive du jugement critique et d'une identité professionnelle parmi les interprètes, ce qui suggère d'explorer plus profondément l'effet de la formation actorale continue pour les personnes atteintes de maladie mentale.

\section{Mots clés}

Désinstitutionnalisation ; éducation théâtrale ; identité professionnelle ; pratiques d'écriture ; trajectoires textuelles

Recontextualizações no convívio pré-cênico: uma modalidade de ensino da noção de conflito à atores com problemas de saúde mental

\section{Resumo}

Tomando do campo teatral a noção de práticas de escrita diversas e da sociolinguística a noção de trajetórias textuais, o artigo descreve a experiência didática conduzida pelo grupoescola de teatro El Brote, radicado desde 1997 na cidade de Bariloche, província de Rio Negro, Patagônia argentina, cujos atores e atrizes são pessoas com problemas de saúde mental e em situação de desmanicomialização. 0 artigo ilustra em particular, o ensino do conceito de conflito junto a estes atores durante o período de dois anos. A metodologia utilizada foi a reescrita de improvisações surgidas no convívio pré-cênico até sua condensação em um texto pré-cênico de autor. Os resultados da experiência mostram a ascensão progressiva do juízo crítico e de uma identidade profissional, o que sugere explorar mais profundamente o efeito do ensino teatral sustentado sobre pessoas com problemas psíquicos.

\section{Palavras chave}

Desmanicomialização; didática do teatro; identidade profissional; práticas de escrita; trajetórias textuais

\section{Ikuti iuiarispa ñugpamanda kaugsai ruraikuna llapa llakichinakuspa umita ungugkunaua}

\section{Maillallachiska}

Kai ruraipi munaku parlangapa imasami kilkaskunata umita ungui llukaskakuna. Nispa paipur llakichinakuska paikuna kaskakunasi Argentina suti llagtamanda. Paikunapas iuiarispa nukanchisina munankuna ruraikuna kawaringa ñugpamandata. Tiami achkakilkaska nukanchi suura mana munanchi paikuna ruraska ñugpasinama, katichinga. Chimanda paikunapa: Ilakirinkuna.

\section{Rimangapa ministidukuna}

Llugsi allilla kaura; imasapas ruraita iachachii; imasa nuka kaska; iachachi kilkangapa; kilkai ñugpachig 


\section{Introducción}

El presente artículo describe la experiencia didáctica llevada adelante por el grupo teatral El Brote, radicado en la ciudad de Bariloche, provincia de Río Negro, Patagonia Norte argentina. Los actores y actrices de El Brote son personas con padecimientos de salud mental en situación de desmanicomialización, gracias a que, en Río Negro, rige desde 1991 la Ley 2440 de Promoción sanitaria y social de las personas que padecen sufrimiento mental, pionera en legislar la desmanicomialización en la Argentina. Muchos autores coinciden en que, al prohibir la habilitación y el funcionamiento de manicomios, neuropsiquiátricos o cualquier institución equivalente en los ámbitos público y privado, esta ley posibilitó la sustitución de la cultura manicomial por una cultura de inclusión y derechos (Cohen y Natella, 2013; Chiarvetti, 2008). No obstante, algunos de estos autores plantean también que la ley fue insuficiente en tanto no estuvo acompañada de la creación de un abanico de programas orientados a responder de manera integral a las necesidades de prevención y tratamiento de los problemas de salud mental (Paulin Devallis, Baffo y Onocko Campos, 2016; Sans, 2013). De hecho, la ley no menciona en ningún caso el papel del arte y la cultura en la desmanicomialización.

No obstante, en Río Negro son significativas las experiencias de trabajo desde el arte que, con modalidades y trayectorias distintas, trataron de salvar la escasez de programas estatales para integrar usuarios de salud mental. El grupo teatral El Brote, fundado en 1997 como asociación civil, fue la primera de esas experiencias rionegrinas de articulación del arte y la salud mental. Así, cuenta con un grupo estable de actores y con la misma directora hasta la actualidad, lo cual constituye una circunstancia bastante excepcional en el país, dado que en las restantes provincias prevalecen los hospitales psiquiátricos públicos o privados $\mathrm{y}$, por tanto, la relación entre el arte teatral y la salud mental se desarrolla no a través de escuelas-grupo sino, predominantemente, de talleres dictados en hospitales monovalentes, o en áreas de salud mental de hospitales generales.

Los diferentes trabajos sobre teatro y salud mental en Argentina basados en experiencias donde aún existe el manicomio (Dubatti y Pansera, 2006; Sava, 2008a, 2008b; Schnell, 2010) ponen el énfasis en lo que dichos talleres de teatro aportan a las personas con padecimiento psiquiátrico. En cambio, el tiempo de trabajo conjunto de El Brote permite hacer un movimiento inverso, que se enfoque en lo que las personas que padecen enfermedades mentales aportan al teatro al constituirse agentes de la dramaturgia. Es decir, se trata de un doble trabajo: formar(se) como actor o actriz y, durante el proceso formativo, producir teatro.

Los límites de este artículo nos impiden detenernos tanto en el trabajo formativo como en el trabajo creativo. Por esta razón, y también porque el detalle de las estrategias didácticas adoptadas para la formación de actores "locos" es escaso (ver, por ejemplo, el tratamiento de la larga experiencia del Frente de Artistas de El Borda en Pansera, 2016), nos abocaremos al trabajo formativo de El Brote, considerando un proceso de enseñanza y aprendizaje específico alrededor del conflicto teatral.

En primer lugar, reseñaremos los referentes conceptuales en los que se basa el análisis: la noción de prácticas de escritura teatral diversas de Jorge Dubatti (2007) y el concepto de trayectorias textuales procedente de la sociolingüística (Blommaert, 2005). En segundo lugar, detallaremos una de las metodologías utilizadas para enseñar la noción de conflicto a los actores de El Brote, consistente en reescrituras en el convivio preescénico hasta la escritura preescénica de autor tras un proceso de discusión en el grupo. En tercer lugar, basándonos en entrevistas realizadas durante 2017 y 2018 a una de las actrices, mostraremos los resultados del proceso de enseñanza y aprendizaje en términos de una asunción progresiva de juicio crítico e identidad profesional. Estos resultados sugieren la importancia de profundizar en la formación sostenida de los actores con padecimientos de salud mental.

\section{Referentes conceptuales - Prácticas de escritura teatral}

Desde el campo del estudio teatral argentino de la postdictadura, Dubatti (2007a) enfatiza en que, entre los cambios aportados por dicho campo, se encuentra el reconocimiento de prácticas de escritura muy diversas en oposición a la idea de que quien escribe teatro es solo el autor que registra una obra. Así, Dubatti (2007a ) afirma que es dramático "todo texto dotado de virtualidad escénica o que, en un proceso de escenificación, ha sido atravesado por las matrices constitutivas de la teatralidad, considerando esta última como resultado de la imbricación de tres acontecimientos: el convivial, el poiético y el expectatorial" (p. 16). En esta línea, considera preciso distinguir, al menos, entre tres textos teatrales: el texto preescénico, dotado 
de potencialidad escénica y escrito o reescrito antes del contexto de la puesta en escena; el texto escénico, conformado por la unidad verbal y no verbal que se realiza en el contexto de cada función, y el texto postescénico, producido mediante reescrituras que transforman el texto escénico.

Además, Dubatti (2007a) sostiene que estas diversas instancias de la composición teatral permiten reconocer diferentes tipos de dramaturgias: la dramaturgia de autor, de director, de actor y de grupo, con sus respectivas combinaciones e hibridaciones $y$, las tres últimas, englobables en el concepto de dramaturgia de escena. La dramaturgia de autor es la producida por los autores que crean textos teatrales preescénicos, antes e independientemente de la labor de dirección o actuación. La dramaturgia de director es la generada por el director cuando (re)crea una obra a partir de la escritura escénica, muchas veces tomando como disparador un texto anterior y recontextualizándolo. La dramaturgia de actor es la que producen los actores mismos cuando sobrepasan la interpretación de un texto y de un personaje y generan una composición con valor en sí mismo (Barba, 2010). La dramaturgia grupal comprende diversas variantes de la composición en colaboración de textos preescénicos, escénicos y postescénicos.

Como efecto de la ampliación del concepto de dramaturgia, es posible otorgar estatuto de texto dramático a formas de escritura que no se corresponden con la notación dramatúrgica convencional en el siglo XIX. En este trabajo, asumimos que la reescritura de improvisaciones de actores conforma una serie de textos preescénicos inscritos en la dramaturgia grupal y que conducen a la reescritura de un texto escénico inscrito en la dramaturgia de autor. Además, como buscamos describir acciones formativas, nos detenemos en la instancia convivial, que nos resulta más interesante para ello: el convivio preteatral que "se inicia en la larga tarea de los ensayos y el trabajo grupal de preparación del espectáculo, ya sea en el proceso creador antes del estreno y funciones de pre-estreno o en las horas de preparativos previas a cada función" (Dubatti, 2007b, p. 66).

\section{Trayectorias textuales}

En el campo de la sociolingüística, se observa un interés creciente en enfoques dinámicos para el análisis de los textos. Theresa Lillis (2013) y Janet Maybin (2017) reseñan muy diversos trabajos que buscan capturar los cambios, direccionalidades y relaciones de los textos a través del espacio y el tiempo. Jan Blommaert (2005) propone la noción de trayectorias textuales para enfocar cómo se crean los textos a través de diferentes procesos de entextualización (o puesta en texto) y recontextualización (o puesta del texto en un nuevo contexto). Al rastrear las trayectorias textuales es posible reconstruir no solo qué cambia en los textos, sino también quién está involucrado, por qué, bajo qué condiciones y con qué consecuencias. En este trabajo, procuramos describir, además de un proceso de transformación textual, la participación de los actores de El Brote en la transformación y las consecuencias para su identidad y sus juicios como co-dramaturgos de grupo.

Los trabajos en la línea de las trayectorias textuales tienen focos de atención específicos. Uno de ellos se detiene en las consecuencias de las trayectorias textuales para individuos particulares, como un migrante cuya historia oral es malinterpretada y reinterpretada por escrito y resulta deportado (Blommaert, 2005) y unos académicos de países "periféricos" que envían un artículo a una revista inglesa lo ven profundamente modificado por los editores hasta que las ideas originales terminan desplazadas (Lillis y Curry, 2010). La conclusión de estos estudios es que, a lo largo de la trayectoria, se producen pérdidas de detalles contextuales, historia y voz del sujeto por factores de poder y desigualdad. Una minoría de autores, sin embargo, obtiene conclusiones en contrario, es decir, que existen entextualizaciones y recontextualizaciones en las que se habla o escribe sin pérdida de voz y con involucramiento activo del otro. Maybin (2017) cita dos trabajos publicados en 2017, uno del campo judicial y otro del campo del periodismo. Como parte del proceso formativo que intentamos describir, en este trabajo buscamos, en sucesivas entextualizaciones y entrevistas, huellas de las voces de los actores de El Brote en relación con la creación textual dramática, así como de su identidad como actores.

\section{Metodología}

En cuanto a los sujetos participantes en la indagación del proceso formativo, se trató de seis actores y actrices, la directora de El Brote y, más indirectamente, el autor de una obra teatral escrita especialmente para El Brote y titulada No está loco quien pelea, Humberto "Coco" Martínez (2011).

Para realizar el análisis del trabajo didáctico, se tomó un corpus constituido por un cuaderno de trabajo y 
diario personal llevado adelante en el año 2000 por una de las actrices, a la que llamaremos Guille, cedido a la directora del grupo teatral; un cuaderno de trabajo de la directora de los años 2006 a 2008; el texto registrado de la obra de Martínez No está loco quien pelea (2011) y dos entrevistas realizadas a Guille, la actriz autora del cuaderno-diario, en los años 2017 y $2018 .^{1}$

El corpus fue analizado con métodos del análisis del discurso tendientes a comparar entextualizaciones y recontextualizaciones con foco entextual para desde allí ascender a lo contextual (por ejemplo, Fairclough, 2001) y captar diferentes posicionamientos de los actores a lo largo del tiempo y en el contexto del grupo-escuela. La inclusión de entrevistas respondió a la búsqueda de sumar una perspectiva emic, es decir, desde el punto de vista de los actores, a fin de establecer relaciones válidas con lo que identificábamos como investigadoras.

Finalmente, en este trabajo hay además un foco de análisis en el contenido de enseñanza conflicto teatral, tal como lo definió Raúl Serrano (1982): "el choque o la colisión entre dos o más fuerzas, y no simplemente una situación afligente o dolorosa" (p. 92).

\section{Resultados}

En este punto abordamos la entextualización y recontextualización condensada de improvisaciones de los actores de El Brote como estrategia didáctica. Usamos la expresión recontextualización condensada para designar un proceso de enseñanza consistente en favorecer una serie de improvisaciones y tomar de ellas solo un conflicto para ser incorporado en una obra, debatiendo con los actores sobre qué es un conflicto. Los objetivos de enseñanza en este caso son, principalmente, dos. Por un lado, propiciar que los actores reconozcan de qué modo los temas que traen recurrentemente al grupo desde sus experiencias pueden acotarse e insertarse en obras de acuerdo con la propuesta dramatúrgica de El Brote. Parafraseando a Dubatti (2010), se busca favorecer la formación en la dramaturgia de actor en interacción con la dramaturgia de director, lo que resulta en una particular dramaturgia de grupo, partiendo de la valoración positiva de los intereses e inquietudes que comparten los integrantes. Este tipo de valoración es crucial para la inclusión y profesionalización de personas que resultan marginadas en muchos ámbitos de participación. Por otro lado, al trabajar con la condensación de improvisaciones, se procura también formar al grupo en el reconocimiento de lo que, en la ficción teatral, es inquietante o no para el espectador (Pricco, 2015). En efecto, en el transcurso de las improvisaciones puede resultar cómodo dar un final rápido al conflicto pero, siendo el conflicto un rasgo constitutivo de la estructura dramática (Serrano, 1982), es más interesante para la formación actoral dejarlo abierto y desarrollarlo.

Organizamos los resultados en tres apartados. En el primero, transcribimos una escena de No está loco quien pelea, señalamos en ella la condensación de improvisaciones y describimos la estrategia de entextualizar improvisaciones. En el segundo, reconstruimos la trayectoria de esa condensación tomando el cuaderno de trabajo 2006-2008 de la directora y mostrando cómo se recontextualizan los textos preescénicos de los actores y cómo dan lugar a un texto preescénico de autor. En el tercer apartado, con foco en la dramaturgia de dirección, nos detenemos en el conflicto como contenido de enseñanza y en cómo lo incorporan los actores revelando juicio crítico y una identidad profesional progresiva.

\section{La condensación}

El texto preescénico de la obra No está loco quien pelea fue escrito por Humberto Martínez (2011), pero él recontextualizó algunas improvisaciones que el grupo realizaba desde tiempo atrás y que la directora había entextualizado en papel. A continuación, transcribimos la escena titulada "La Muerte y Guille", señalamos la condensación y justificamos el registro de improvisaciones en papel. Analizamos las improvisaciones en el apartado siguiente.

\section{Escena 7. La Muerte y Guille}

Muerte: (Se acerca a la Actriz y el viento cesa. Toma la tela). No es lo mismo ser profundo que haberse venido abajo...

Actriz: (Indignada y furiosa). ¿iYo!?

Muerte: (Se burla). Ellaaaa, ellaaaa. (Mira fijamente a la Actriz y retuerce la tela entre sus manos como si fuera su pescuezo, pero esta no cede. Luego lo intenta con Guille y funciona). 


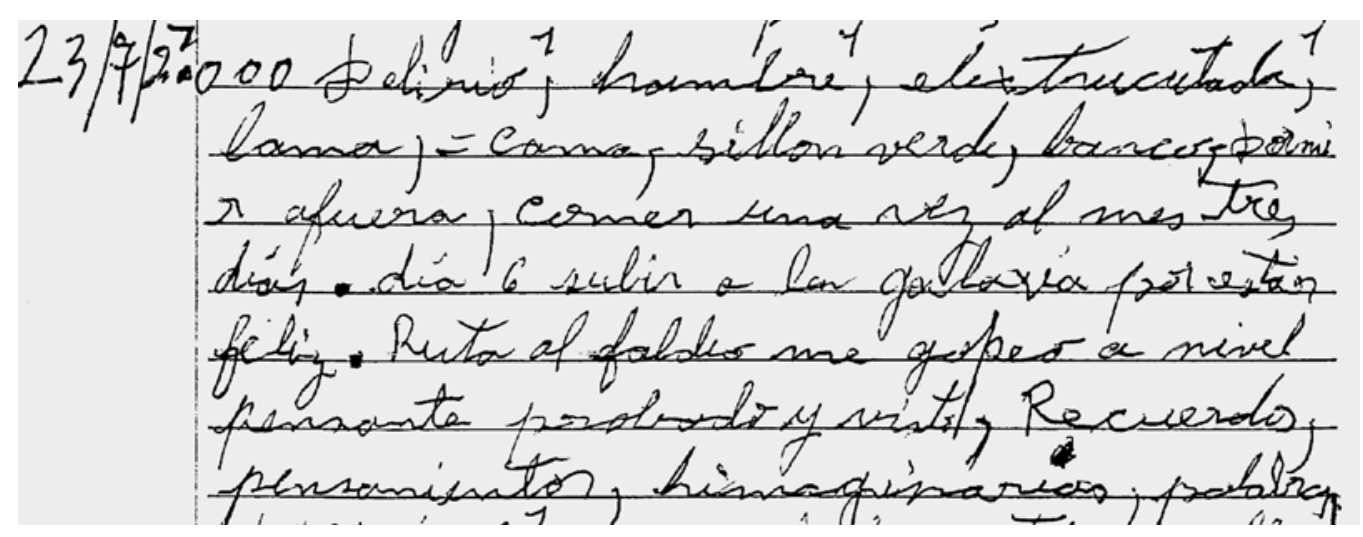

Imagen 1. Extracto de la página 25 del cuaderno-diario escrito en el año 2000 por Guille, unas de las actrices de El Brote.

Guillermina: iAy! No me quiero morir, no me quiero morir... iMe voy a morir, me voy a morir! iMe morí! (Se desploma).

Muerte: (Cubriéndola con la sábana). Yo no hice nada, te moriste sola. (Cantando). Solita y sola.

(Se desplaza hacia su lugar caminando lentamente con Guille, que gatea bajo la tela).

Guillermina: Quisiera ir al fondo del mar, para juntar monedas de lata, el pan mojado, los cigarrillos mojados... Pero no sé nadar. ¿Y si me enseñan a nadar? (En ese momento se descubre de la tela y ve a la Muerte. Se levanta y corre asustada hacia la Actriz). iAy, la gran flauta!

(La Muerte la corre para que no se escape, la Actriz protege a Guillermina atajando a la Muerte con la silla de ruedas y la muñeca. La Muerte, furiosa, toma la tela y comienza a moverse como un torero. Música en vivo la acompaña y, en cada OLE, que el resto acompaña con palmas, amenaza a alguien. Termina su danza).

Muerte: (Saluda, vanidosa). ¿Y? ¿Cómo estuve? (Todos aplauden y festejan). (...)

Muerte. Gracias, gracias... Pero esto... no los salva. (Martínez, 2011; p. 15).

La condensación incluida en la escena es la siguiente:

Quisiera ir al fondo del mar, para juntar monedas de lata, el pan mojado, los cigarrillos mojados... Pero no sé nadar. ¿Y si me enseñan a nadar?
Esta condensación fue el resultado de improvisaciones que se entextualizaron a lo largo de dos años de clases. Las razones de la entextualización de improvisaciones para su recontextualización en obras de El Brote son dos. Por un lado, partir de las realidades de los actores para construir una poética arraigada en su experiencia vital y no en una pretensión estética de autor o a priori. Por otro, posibilitar que el "delirio" deje de ser una vivencia limitante y se convierta en conciencia de representación, con posibilidades de mudanza y metáfora. Para los actores que conforman el Brote, el delirio es, en efecto, una vivencia atroz que requiere ser resignificada, como evidencia este segmento de entrevista a Guille:

Me pasó algo horrible que... no sé todavía bien que es. Yo le llamo "delirio", pero... fue algo de la pérdida de la memoria y no estar consciente de lo que hacía y... ni saber si era de día o si era de noche... o que día, qué mes, qué año, qué hora, no sabía nada. Nada, nada, nada, porque perdí..., yo digo que perdí los sentidos (Entrevista a Guille, 2017).

En el segmento presentado, se observa una distancia considerable de Guille respecto de su "delirio", es decir, este parece ser el recuerdo de algo pasado que puede comunicar a otros. Pero en su cuaderno de trabajo y diario personal del año 2000, el "delirio" estaba mucho más próximo, como puede observarse en la Imagen 1 y la transcripción siguiente:2

23/7/2.000 Delirio, hambre, elextrocutada, Cama, = cama, sillon verde, banco, dormir afuera, comer

\footnotetext{
2 En la transcripción de textos escritos por los actores y la direc tora, se conservan la ortografía y la puntuación de los originales pues, aunque presenten errores normativos, dan cuenta de situaciones de comunicación reales y específicas.
} 
una vez al mes tres días. día 6 subir a la galaxia por estar feliz. Ruta al faldeo me golpeo a nivel pesante probado y visto, Recuerdos, pensamientos, himaginarios, palabras.

Diecisiete años antes de la entrevista, en su cuaderno-diario, Guille identificaba — para sí, pues no se trataba de textos para compartir con otros- el "delirio" con la internación, la exclusión, la pobreza y un dato clave para ella: el "delirio" la había golpeado indudablemente a "nivel pensante", es decir, había afectado su pensamiento, sus recuerdos, su imaginación y su discurso. Si bien se trata de solo dos ejemplos de los tantos acumulados en la experiencia de El Brote, sirven para ilustrar el punto de partida de los actores y actrices y el trabajo que debe realizarse y se realiza con ellos para que el "delirio" se transforme en metáfora y creación.

A continuación, exponemos el proceso de entextualizaciones que llevó a la condensación presente en la escena "La Muerte y Guille".

\section{La entextualización de improvisaciones}

La serie de improvisaciones que dio lugar a la condensación presentada en el apartado anterior surgió del interés de Guille en el tema del mar. ${ }^{3}$ A continuación, transcribimos, respetando la ortografía del original, una improvisación de Guille sobre el tema del mar entextualizada por la directora del grupo el 6 de noviembre de 2006 (se reproduce la página del cuaderno de trabajo de la directora en la Imagen 2). ${ }^{4}$

\section{Improvisación del 6/11/2006}

Guille: Qué tranquilo que está el mar no se siente ni un ruido las olas se han quedado quietas mejor para mí, no sé nadar.

Irá a venir más gente al mar?... no sé se pueden ir todos hacia el fondo del mar se pueden ir
3 Guille, nacida en el interior de la Patagonia Norte, conoció el mar en un viaje que El Brote realizó a la ciudad bonaerense de Mar del Plata en 1997, para participar del V Festival Latinoamericano de Artistas Internados y Externados de Hospitales Psiquiátricos. Desde entonces, el mar se volvió un tópico de su discurso.

En las entextualizaciones, el pasaje de una línea a otra representa las pausas del discurso oral de los actores; el uso de paréntesis indica comentarios aclaratorios de los actores; la agrupación de partes del texto mediante llaves señala el interés de la directora en retomar posteriormente alguna de las unidades de sentido.
No me gusta el mar, me da miedo.

Está borrascoso el mar.

Yo no sé por qué en alguna parte se oyen voces

debe ser el viento que silba

Sí, el viento...

Qué lindo sería que aparezca una musa...

(junto con la bruma)

Sí pero puede haber bruma en el mar porque la musa podría venir vestida de celeste y acercarse y ayudarme a correr las olas si supiera nadar yo podría pasar sobre las olas.

Considerando la variedad dialectal del español de la Norpatagonia, en esta improvisación se observan expresiones interesantes: la actriz combina un uso oral popular ("se pueden ir todos hacia el fondo del mar se pueden ir"), con otro coloquial ("mejor para mí", "me da miedo", "qué lindo sería", "en alguna parte se oyen") y otro poético o literario ("borrascoso", "musa", "bruma"5). Además, Guille expresa imágenes potentes: el mar como un lugar adonde enviar a los "intrusos", como algo bello $y$, finalmente, como algo que infunde miedo y deseo de ayuda. Tanto los variados usos del lenguaje como la contraposición que establecen las imágenes son considerados elementos con potencialidad dramática, por lo que se retoma el tema del mar en nuevas improvisaciones. En la siguiente página del cuaderno de la directora, reproducida en la Imagen 3 y transcrita a continuación, se observa la incorporación de otros actores en la improvisación:

Entextualización de la improvisación del 6/11/2006 (continuación)

\section{(...)}

Matías: (Le pide). Una monedita.

Guille: Suenan las campanas como si fueran monedas pero no son monedas son pedazos de lata que ha traído a la orilla, sí pedacitos de lata.

Lydia: (Le pide). Un cigarrillo.

Guille: En el mar no se fuma

en el mar se te va a apagar el cigarrillo.

Julieta: (Le pide). Un pedazo de comida por favor Sra.

Guille: El mar es tan amplio se parece

$5 \quad$ No queremos afirmar que el registro literario está conformado solo por términos de uso menos frecuente, sino proponer que, desde la perspectiva de Guille, ciertos términos son más "elevados" que otros. 
un poco al océano

se lo cruzará al mar?

se debe ir por la orilla

si yo me pudiera ir por la orilla me iría...

podría irme, pero no, me quedo acá entre las olas.

Estos actores actúan como testigos dispuestos a intervenir. La directora les había propuesto que, mientras Guille hablaba, realizaran pedidos de algunos elementos que ella había mencionado en una de las improvisaciones anteriores: monedas, cigarrillos, trozos de pan. Según la consigna, cada uno podía elegir qué pedir y cómo, sin detener el flujo de la improvisación, y Guille debía reaccionar a cada una de las intervenciones. El objetivo de la consigna, en línea con los objetivos generales expuestos en el apartado anterior, era que todos los actores se involucraran en el aprendizaje de dramaturgia de grupo. Los actores formulan pedidos. Guille reacciona respondiendo negativamente o no respondiendo, lo que genera tensión; sostiene el uso de un registro coloquial ("pedacitos de lata") y otro más literario-poético ("suenan las campanas como si fueran monedas"), e introduce información nueva: el mar es intrigante y genera preguntas.

La improvisación continúa en una clase posterior. Al comienzo, está básicamente a cargo de Guille, ya que los restantes actores y actrices no formulan pedidos y es ella quien solicita, dirigiéndose a la musa, "Tiéndame una mano, señora, tengo hambre". Es decir, Guille mantiene el hilo de los pedidos y, además, la idea del miedo al mar ("pero yo no sé nadar") y de lo que el mar no provee ("pero no son monedas/son latas que suenan"). Los restantes actores retoman los actos de pedido más adelante:

Entextualización de la improvisación del 7/11/2006

Lydia: Un cigarrillo por favor

Guille: El mar...¿a cuántas personas se ha devorado? Se ha aquietado el mar.

Enri: ¿Me convida un mate?

Guille: El mar...las caracolas

Sí debe ser hermoso el fondo del mar con todos los colores.

Elina: Un pedazo de pan por favor

Guille: Y las cavernas que habrá peces de colores sí peces de colores
En la improvisación está presente como texto recontextualizado la letra de la canción "Alfonsina y el mar", que en aquel momento se abordaba en el Taller de Música de El Brote. Guille retoma figuras de la canción (el fondo del mar, las caracolas) y aporta creaciones de su imaginario. Por ejemplo, el personaje de la mujer fascinada por conocer las profundidades del mar y a la vez atemorizada por ellas y lo que devoran y, por tanto, que se llama a quedarse quieta, como se ve también en las entextualizaciones anteriores, o a pedir auxilio, como se observa en la próxima entextualización. Desde el punto de vista de la dramaturgia, tienen potencial las imágenes de las monedas de lata, así como los cigarrillos y el pan mojados, elementos surgidos en una improvisación pasada, que Guille encontraba en el mar y en este caso recontextualizan los restantes actores, alcanzando el objetivo de aprender una dramaturgia de grupo. Desde el punto de vista discursivo, los elementos enumerados remiten a un discurso sobre la pobreza y la necesidad, en contraste con otro discurso en el que el mar y sus posesiones ("todos los colores", "las cavernas", "caracolas", "sí peces de colores") son inconmensurables, pero retaceados ("pero no son monedas/son pedazos de lata"). Todo esto resulta potente para la recontextualización en un texto preescénico.

Para dar lugar a ensayos que tenían prioridad para El Brote, las improvisaciones sobre el mar se retoman en las clases 20 días después de las anteriores: Entextualización de la improvisación del
27/11/2006

Guille: el mar está borrascoso las olas se mecen no se fuma en el mar el mar te toma y te lleva

Otros compañeros/as: Una moneda? Una moneda?

Guille: en el mar se pudre el pan llamemos a la musa...

Guille se detiene y la directora propone que recontextualice la improvisación otro actor, Fernando. Reproducimos un fragmento de su aporte:

Entextualización de la improvisación del 27/11/2006 (continuación)

Fernando: Cuántos albatros, cuánta furia

$6 \quad$ Creada por Ariel Ramírez y Félix Luna y grabada por primera vez en 1969 por Mercedes Sosa. 


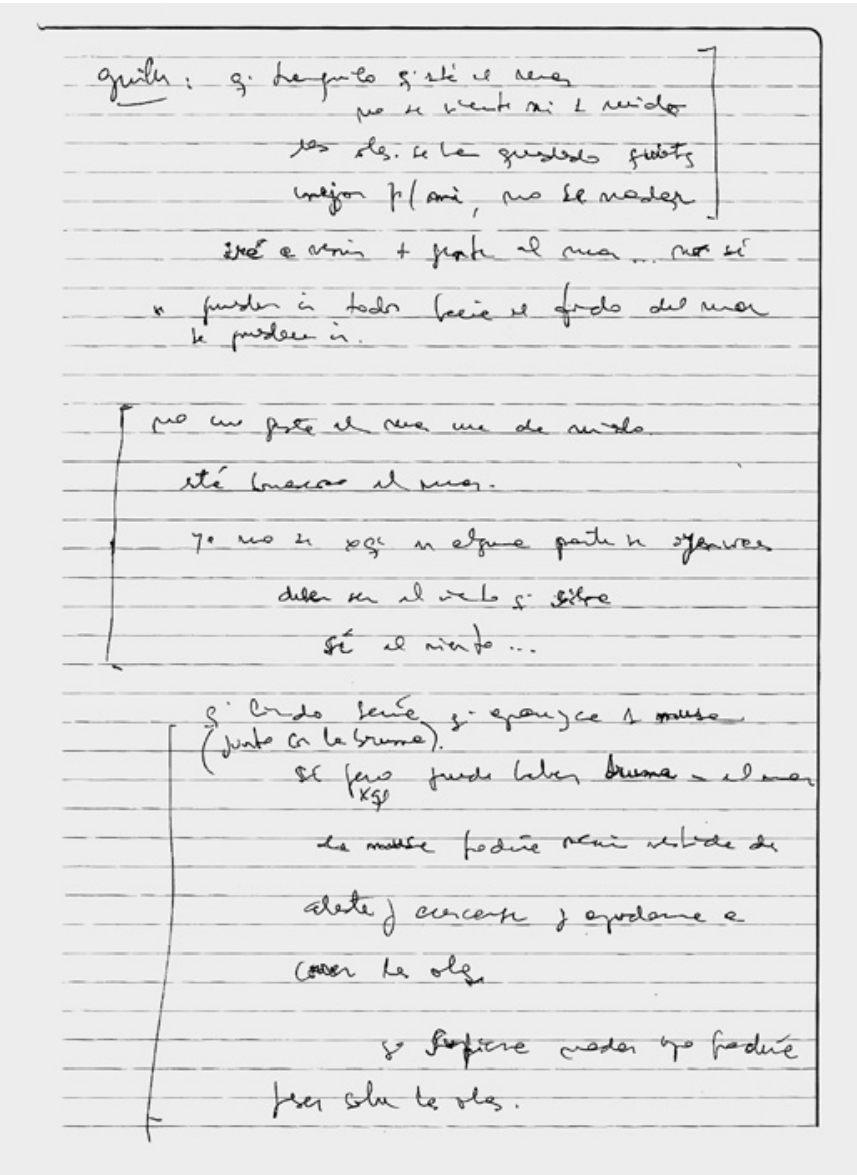

Imagen 2. Reproducción de la página 66 del cuaderno de trabajo 20062008 de la directora de El Brote. Se observa la entextualización manuscrita de una improvisación sobre el mar de una de las actrices, Guille.

será así siempre tendrá ese color verde oscuro debemos esperar a que nos tape alguna vez esos vientos que se cruzan a lo lejos deben estar los veleros surcando toda esta inmensidad

Un compañero: ¿Un cigarrillo por favor?

Fernando: Esa luna no fuma y el cigarrillo tampoco es fumado en este mar ancho.

Una compañera: ¿Una monedita por favor?

Fernando: Se escuchan a lo lejos los crujidos de los caños de las velas, los remos, quién se tira a la aventura en este mar tan grande, tan ancho, tan alto $(. .$.

La estrategia didáctica subyacente a la indicación de que Fernando retome el tema aportado por Guille es que ella - u otro actor, en otro caso- pueda verse reflejada en otro discurso y complementada por nuevas imágenes. Las recontextualizaciones por parte de otros actores se

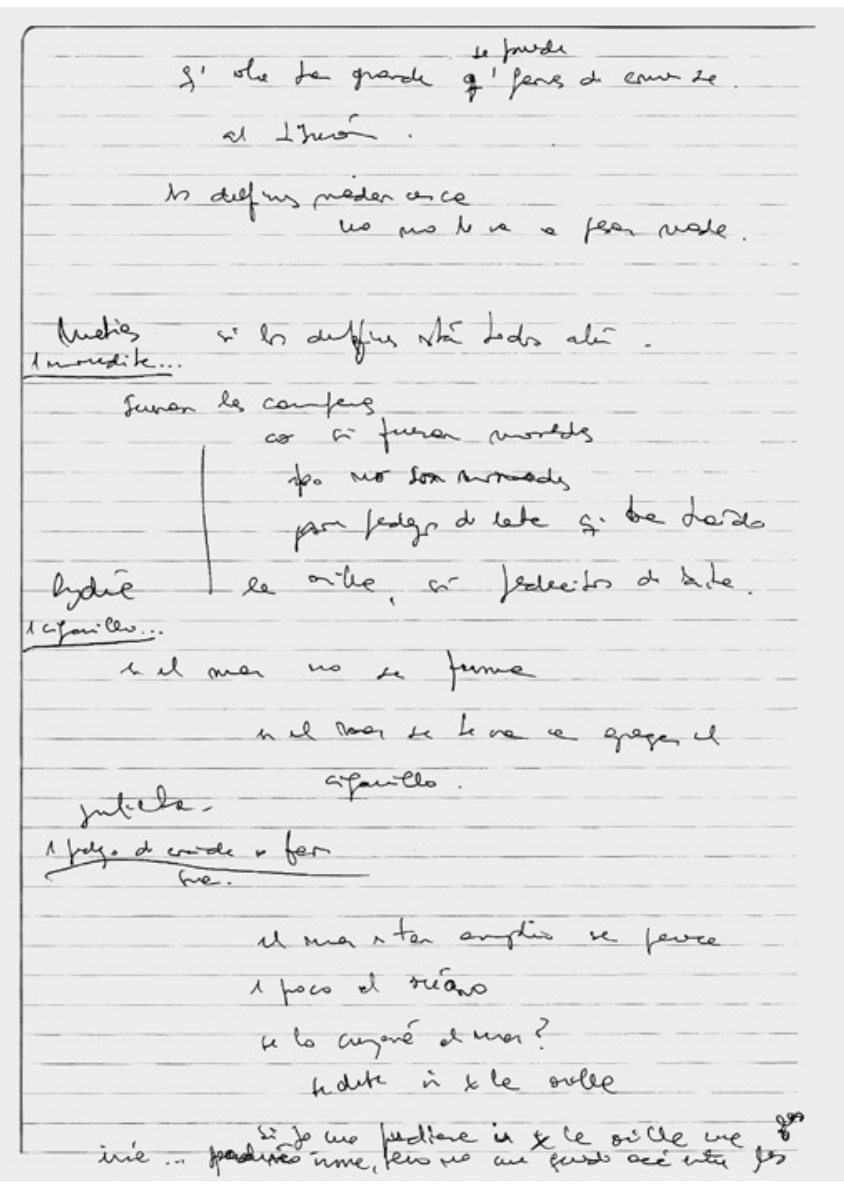

Imagen 3. Reproducción de la página 67 del cuaderno de trabajo 2006 2008 de la directora de El Brote. Continuación de la entextualización de la improvisación sobre el mar, en la que interactúan varios actores.

consideran fundamentales para enseñar en qué consiste la dramaturgia de grupo en El Brote, así como para favorecer la integración del yo a través de la interacción con otros. En palabras de Trozzo (2015), “El teatro entrena para construir espejos en los que las personas puedan mirar la humanidad que hay en ellas mismas" (p. 16), y esto no solo sucede en el acontecimiento escénico, sino también en los innumerables textos que lo preceden y tienen como función la formación y la agencia de los actores, pilares para la producción teatral.

Las entextualizaciones en el cuaderno de la directora sobre el mismo tema reaparecen al año siguiente, en el mes de julio; las transcribimos a continuación (ver el original en la Imagen 4).

\section{Entextualización de la improvisación del 06/07/2007}

Guille: Hoy el mar está borrascoso parece que va a haber neblina y si viniera una musa inspiradora y me ayudara con las olas por qué no sé nadar? (...) 
Qué es eso que hay en el fondo del mar se podría construir una casa en el fondo del mar una casa llena de corales, donde vayan los peces, en el fondo del mar y después una ventana al cielo

Un compañero: Un vaso de agua

Guille: Está salada el agua

Una compañera: Un pedazo de pan

Guille: Pan mojado únicamente

Un compañero: Una monedita por favor

Guille: Monedas de lata únicamente puchos de cigarrillo

Un compañero: Ayúdame, señora?

Guille: Qué lo puedo ayudar...a hundirse más para que se vaya a la profundidad del mar $\rightarrow$ (Le indica a un compañero). Alcáncele la musa un camarón a mi derecha o a mi izquierda otro... $\rightarrow$ (Le indica a un compañero). Corran las musas vengan a servirme
Al comienzo, aparecen tópicos que Guille venía explorando, como la borrasca, el miedo por no saber nadar y el deseo de la musa, y también un nuevo tópico: el mar como un espacio a ser ocupado. El pedido de un vaso de agua y la respuesta "está salada el agua" también son nuevos, aunque sostienen la línea de las necesidades que el mar no satisface. Pero, hacia el final, estas necesidades llegan a un remate. Cuando el compañero pide ayuda a Guille, esta responde que lo puede ayudar a hundirse más para que se vaya al fondo del mar y, como cansada de los pedidos, pasa a asumir un rol de "señora del mar" dando órdenes a sus sirvientas, las musas. Con esto, Guille daba pie a los restantes actores para que reaccionaran a las órdenes. Pero ellos no reaccionaron.

\section{La enseñanza de la noción de conflicto}

La improvisación se detuvo en el punto mencionado porque el grupo avanzaba hacia una resolución fácil: las musas cumpliendo prontamente con los pedidos de los necesitados. Se inició así una conversación alrededor de la idea de que esas musas obedientes, en vez de aprovechar los conflictos potenciales, los hacían desaparecer apagando, al mismo tiempo, el interés del espectador, en este caso, de la directora, la primera

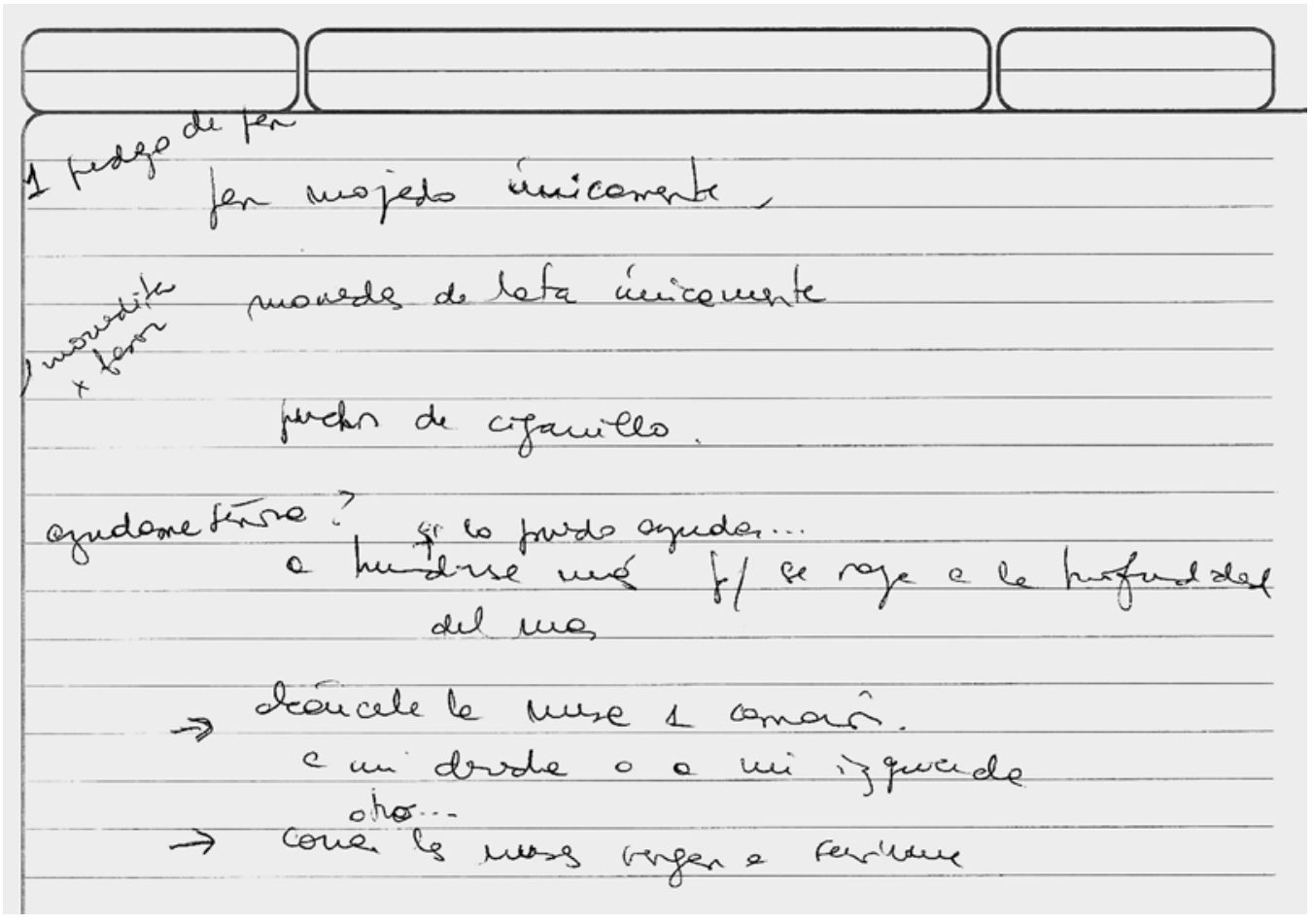

Imagen 4. Reproducción de la página 103 del cuaderno de trabajo 2006-2008 de la directora de El Brote. Corresponde a la última de las improvisaciones de los actores sobre el tema del mar. 
espectadora, retomando la conceptualización de Barba (2010). Se conversó que, desde el momento en que Guille ordenaba y los demás se disponían a cumplir, se perdía la idea fuerza del mar mezquino sin que fuera sustituida por otra idea desequilibrante. Se planteó que, en el juego de la ficción, es tentador imaginarles un final feliz a los problemas, pero es más interesante no clausurarlos. Siguiendo a Pricco (2015), se propuso:

una estética (y una didáctica) del desequilibrio, basada en el entrenamiento de la capacidad y la habilidad de jugar actoralmente con el intento de resolución de conflictos de ficción pero buscando, paradójicamente, el "fracaso". (...) "fracasar" en los planes de solución de un problema (...) de manera que el equilibrio precario o el desequilibrio (injusticia, falta de amor, falta de lo necesario para vivir (...)) sea mantenido y tenga, por ende, en vilo al espectador (p. 120).

Compartir reflexiones de este tipo supone asumir que la agenda didáctica debe ser evidente pues, como plantea Trozzo (2015), “la agenda oculta, lejos de promover la creatividad en los otros, es un acto de abandono y un abuso de poder que asfixia las posibilidades de pensar para reordenar" (p. 13). Retomar, a lo largo de improvisaciones, los discursos que los actores llevan a la clase es recuperar lo que para ellos vuelve recurrentemente, pero también, con base en la revisión de entextualizaciones, modificarlo por efecto de la mediación que constituyen la enseñanza y el aprendizaje en grupo -y el proceso creativo, que en El Brote marcha junto con la formación. En la enseñanza del oficio teatral a personas con padecimiento psíquico, dar voz no consiste solo y necesariamente en dejar improvisar. También puede consistir en enseñar en qué momentos se sostuvo un conflicto con verdad escénica, qué acciones resultaron orgánicas y qué reacciones estuvieron vivas. En igual sentido, formar a un actor puede consistir en enseñarle que la actuación exige el aprendizaje de técnicas, particularmente, cuando hay un interés específico en que, construya su expresión a través de una mayor capacidad de auto-registro corporal, que le permita entrar y salir de la ficción con fluidez y potenciar su presencia escénica a través del uso de herramientas del oficio. Los aprendizajes correspondientes no se adquieren de una vez ni tampoco en un período de dos años como el que se toma aquí ilustrativamente: por el contrario, son recursivos e implican ciclos de enseñanza.

Las limitaciones de soporte nos impiden mostrar cómo se manifiestan los aprendizajes de los actores de El
Brote en escena, pero podemos compartir lo que expresan en entrevistas sobre la apropiación de la noción de conflicto y del oficio teatral. En el primer segmento, Guille responde a si sabe qué puede ser más y menos interesante para el público:

Sí, me pasaba mucho con la obra No está loco quien pelea... Por ahí había, este... cosas que eran muy, muy... muy infantiles, y me parecía que tenía que crecer un poco para que el público... ehh... viera en otra dimensión la obra de No está loco quien pelea. Eso me pasaba... No sé en qué parte me pasaba eso de... Yo dije no me tengo que meter porque Gabi es la directora y yo no tengo que meterme. $Y$ lo dejé, pero dije no vamos a ganar, con esta obra no vamos a ganar el primer puesto...Y le dije a Elina "Vamos a salir cuartos" (Entrevista a Guille, 2018).

En el segmento anterior, Guille se pone en el lugar del público -y el del jurado de la Fiesta Provincial del Teatro 2012- para evaluar que, en su opinión, en la obra había "cosas que eran muy infantiles", que debían "crecer" para que el público viera "otra dimensión". Si bien no puede precisar en qué "parte" le pasaba eso, muestra una postura crítica sobre el texto posescénico que evidencia criterios internos para decidir qué es, desde su punto de vista, inquietante o no para el espectador. Además, el segmento muestra un importante posicionamiento de Guille tras más de 20 años de trabajo en El Brote: si bien reconoce la dirección de Gabriela, se considera en posición de formular juicios sobre la obra no solo para sí ("yo dije, no vamos a ganar"), sino también dirigidos a otros, como su compañera Elina.

En el segmento que sigue, Guille responde a una pregunta sobre el aprendizaje de la técnica corporal:

Sí, sí, todo eso, todo eso que hacíamos me... me... me chocaba, me chocaba, me chocaba y no podía. Y... después me sentía peor, porque al contradecir la técnica, viste, terminaba con... contracturada del cuello, del cuerpo, viste, y todo por mi negación. Y eso lo descubrí yo sola porque yo dije, ¿qué estoy haciendo yo? ¿Peleándome con Gabriela que ni se entera que yo me estoy peleando con ella? (Entrevista a Guille, 2018).

En este segmento, Guille evoca sus primeros pasos en el aprendizaje de la técnica y autoevalúa negativamente su resistencia. Plantea, además, que llegó a la 


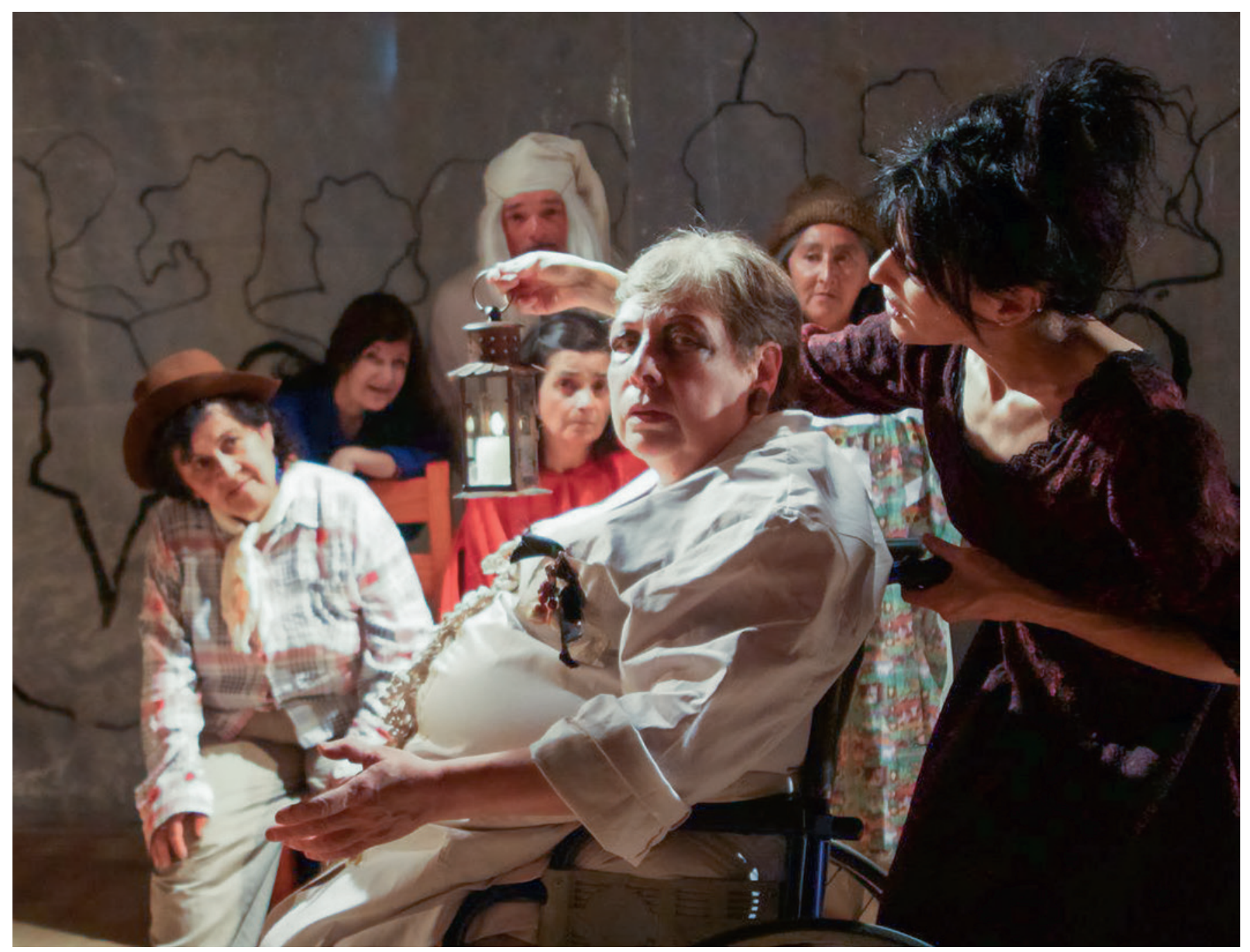

Imagen 5. El grupo El Brote en una escena de No está loco quien pelea. Fotografía: Hebe Medrano. Bariloche, 2013.

conclusión sobre la importancia de la técnica por sí misma, mediante un ejercicio autocrítico.

En suma, en la escena "La muerte y Guille" de No está loco quien pelea (Martínez, 2010), se condensó una larga improvisación del grupo alrededor del tema del mar, a través de un proceso de sucesivas entextualizaciones y recontextualizaciones que posibilitaron trabajar en el convivio preescénico con la noción de conflicto teatral. Después de este trabajo, desde la dramaturgia de dirección se dejó solo el hueso de la exploración para presentarlo a Humberto Martínez como dramaturgo de la obra: las necesidades, el miedo al mar y la muerte y la apertura a los otros para salvarse: "Quisiera ir al fondo del mar, para juntar monedas de lata, el pan mojado, los cigarrillos mojados... Pero no sé nadar. ¿Y si me enseñan a nadar?". La estrategia didáctica (y otras estrategias didácticas anteriores), la creación de esta obra "especialmente para El Brote" (y la creación de obras colectivas anteriores y posteriores), así como la actuación del grupo en ella(s), motivaron el juicio crítico y el aprendizaje progresivo de técnicas por parte de los actores con padecimientos de salud mental que conforman El Brote.

\section{Conclusiones}

En los apartados anteriores, ilustramos una estrategia didáctica empleada en El Brote para lograr que los actores se autoperciban como tales, formulen juicios críticos y aprendan nociones y herramientas del oficio teatral expresándose sin perder su voz e involucrándose activamente en la actividad. Sintéticamente, la estrategia consiste en partir de sus inquietudes e imágenes, entextualizarlas, explorarlas en el convivio como textos preescénicos, hacer que se recontextualicen en los discursos del grupo y la dramaturgia de director o autor, discutirlas en términos de eficacia teatral y favorecer la ejercitación de las herramientas y su conceptualización operativa. 
Este tipo de trabajo - y trabajos con otras modalidades que no alcanzamos a ilustrar aquí- se realiza en El Brote de manera sostenida hace más de 22 años y hace 9 en una sala de teatro propia; con la misma directora y, básicamente, con el mismo grupo de actores, remunerados como tales en el contexto de un grupo de teatro independiente. Los logros de los actores "locos", ilustrados brevemente en el artículo, sugieren la importancia de atender a factores didácticos como los mencionados y también extra-didácticos, como la persistencia en la gestión, la extensión de la enseñanza, el logro de un espacio de trabajo y encuentro, la percepción de un cachet y la posibilidad de ser juzgados por públicos reales. Además, los logros de los actores "locos" reclaman la generalización de políticas de salud más humanas, que erradiquen las variantes del manicomio y extiendan las estructuras y redes necesarias para que todas las personas vivan como ciudadanos con plenos derechos.

\section{Referencias}

Barba, E. (2010). Quemar la casa. Orígenes de un director. Bilbao/Madrid: Artez Blai.

Blommaert, J. (2005). Discourse: A Critical Introduction. Cambridge: Cambridge University Press.

Cohen, H. y Natella, G. (2013). La desmanicomialización: Crónica de la reforma del sistema de Salud Mental en Río Negro. Buenos Aires: Lugar Editorial.

Chiarvetti, S. (2008). La reforma en salud mental en Argentina: una asignatura pendiente. Sobre el artículo "Hacia la construcción de una política en salud mental". Revista Argentina de Clínica Psicológica, 17(2); pp. 173-182.

Dubatti, J. (2007a). Hacia una tipología de textos dramáticos: modos de relación entre el texto y la escena. En O. Pellettieri. Huellas escénicas; pp. 15-28. Buenos Aires: Galerna. (2007b). Filosofía del teatro I. Convivio, experiencia, subjetividad. Buenos Aires: Atuel. . (2010). Filosofía del teatro II. Cuerpo poético y función ontológica. Buenos Aires: Atuel.
Dubatti, J. y Pansera, C. (coords.) (2006). Cuando el Arte da respuestas: 43 proyectos de cultura para el desarrollo social. Buenos Aires: Artes Escénicas.

Fairclough, N. (2001). Language and Power. Harlow: Pearson.

Lillis, T. (2013). Sociolinguistics of Writing. Edinburg: Edinburgh University Press.

Lillis, T. y Curry, M. J. (2010). Academic Writing in a Global Context. London: Routledge.

Martínez, H. (2011). No está loco quien pelea. Buenos Aires: Sociedad General de Autores de la Argentina.

Maybin, J. (2017). Textual trajectories: Theoretical roots and institutional consequences. Text \& Talk, 37(4), pp. 415-435.

Pansera, C. (2016). Teatro y salud. Entre el caos biológico y el arte terapéutico. Buenos Aires: Artes Escénicas.

Pricco, A. (2015). Sostener la inquietud. Teoría y práctica de la actuación teatral según una retórica escénica. Rosario: Biblos.

Sans, D. (2013). Tratar la locura. La judicialización de la salud mental. Buenos Aires: Topía.

Sava, A. (Comp.) (2008a). Arte y desmanicomialización: una puerta a la libertad en hospitales psiquiátricos públicos de Argentina. Buenos Aires: Ediciones Artes Escénicas.

(Coord.) (2008b). Frente de Artistas del Borda. Una experiencia desmanicomializadora. Arte, Iucha y resistencia. Buenos Aires: Editorial Madres de Plaza de Mayo.

Schnell, E. (2010). Un teatro necesario. Relato de una experiencia. Buenos Aires: Artes Escénicas.

Serrano, R. (1982). Los conflictos. En: Dialéctica del trabajo creador del actor; pp. 91-96. México DF: Cartago.

Trozzo, E. (2015). Didáctica del teatro para la educación superior. Viedma: Editorial UNRN. 